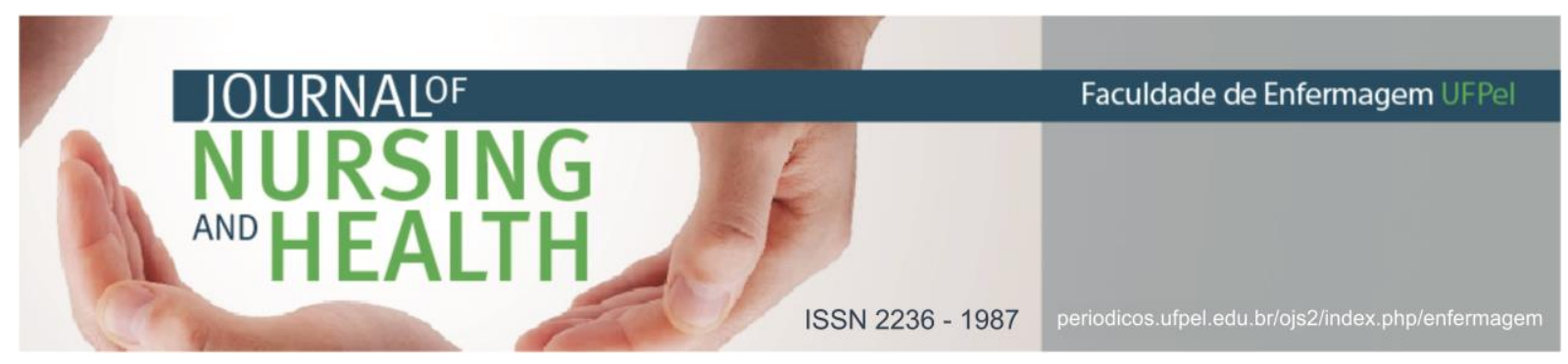

ARTIGO ORIGINAL

\title{
Visitas domiciliares puerperais: promoção da saúde do binômio mãe- filho
}

\author{
Puerperal home visits: health promotion of the mother-baby pair
}

\section{Visitas domiciliarias puerperales: promoción de la salud del binomio madre-hijo}

Hollanda, Gabriela Silva Esteves de ${ }^{\text {; }}$ Lima, Vanessa Kelly da Silva²; Oliveira, Bruna Monik Morais de ${ }^{3}$; Bezerra, Raylla Araújo4; Carvalho, Carolina Maria de Lima5; Santos, Lydia Vieira Freitas dos ${ }^{6}$

Como citar este artigo: Hollanda GSE, Lima VKS, Oliveira BMM, Bezerra RA, Carvalho CML, Santos LVF. Visitas domiciliares puerperais: promoção da saúde do binômio mãe-filho. J. nurs. health. 2019;9(3):e199307

\section{RESUMO}

Objetivo: identificar as principais vivências, necessidades e dúvidas de puérperas de um município do interior do Ceará, com a finalidade de promover a saúde do binômio mãe-filho. Métodos: estudo descritivo de caráter qualitativo realizado no município de Acarape - Ceará, de abril a maio de 2015, com sete puérperas que receberam visita domiciliar, a partir de um convite no grupo de educação em saúde para gestantes. As visitas foram observadas e registradas em diário de campo para a análise de conteúdo dos dados. Resultados: foram elencadas quatro categorias: impressões das puérperas acerca do parto e dúvidas com os acontecimentos no seu corpo no período pós-parto; Atenção aos recémnascidos; Interação mãe e recém-nascido; Planejamento familiar. Considerações Finais: as visitas domiciliares proporcionaram a discussão de temas importantes para as puérperas, de maneira complementar ao pré-natal, tornando-as mais empoderadas diante do autocuidado e do cuidado com o filho recém-nascido.

Descritores: Visita domiciliar; Período pós-parto; Educação em saúde.

\section{ABSTRACT}

Objective: to identify the main experiences, needs and doubts of women in the postpartum period in a municipality in the interior of the state of Ceará, in order to promote the health of the motherbaby pair. Methods: qualitative descriptive study conducted in the city of Acarape - Ceará, from April to May 2015, with seven women at the postpartum period received home visits, from an invitation in the health education group for pregnant women. The visits were observed and data was registered in a field diary for data content analysis. Results: four categories were identified:

1 Enfermeira. Universidade Federal da Paraíba (UFPB), Brasil. E-mail: gabyhollanda@hotmail.com http: / /orcid.org/0000-0002-3612-692X

2 Enfermeira. Universidade da Integração Internacional da Lusofonia Afro-Brasileira (UNILAB), Brasil. E-mail: vanessa.kelly902@gmail.com http://orcid.org/0000-0002-9992-4822

3 Enfermeira. Universidade da Integração Internacional da Lusofonia Afro-Brasileira (UNILAB), Brasil. E-mail: brunamonik.sh@gmail.com http: //orcid.org/0000-0001-5214-897X

4 Enfermeira. Mestra em Enfermagem. Universidade Federal do Ceará (UFC), Brasil. E-mail: lalah_zinha3@hotmail.com http://orcid.org/0000-0002-2781-7817

5 Enfermeira. Doutora em Enfermagem. Universidade da Integração Internacional da Lusofonia Afro-Brasileira (UNILAB). E-mail: carolinacarvalho@unilab.edu.br http://orcid.org/0000-0002-5173-5360

6 Enfermeira. Doutora em Enfermagem. Universidade da Integração Internacional da Lusofonia Afro-Brasileira (UNILAB). E-mail: lydia@unilab.edu.br http://orcid.org/0000-0003-4277-7486 
Women's impressions of childbirth and questions concerning their own bodies during the postpartum; Newborn caring needs; Mother-baby interaction; and Family planning. Final Considerations: the home visits provided discussion of important topics complementing prenatal care and made women empowered to take care of themselves and their newborns.

Descriptors: House calls; Postpartum period; Health education.

\section{RESUMEN}

Objetivo: identificar las principales experiencias, necesidades y dudas de las mujeres después del parto en un municipio del interior de la Ceará, para promover la salud del binomio madre-hijo. Métodos: estudio descriptivo cualitativo realizado en la ciudad de Acarape - Ceará, de abril a mayo de 2015, con siete mujeres posparto que recibieron visitas domiciliarias, luego de una invitación en el grupo de educación sanitaria para mujeres embarazadas. Las visitas se observaron y registraron en un diario de campo para el análisis de contenido de datos. Resultados: se enumeraron cuatro categorías: impresiones de parto de las mujeres posparto y dudas sobre los eventos posparto en su cuerpo; atención a los recién nacidos; interacción madre y recién nacido; planificación familiar. Consideraciones Finales: las visitas domiciliarias brindaron una discusión sobre importantes temas posparto, complementando la atención prenatal, haciéndolas más capacitadas frente al autocuidado y cuidado del recién nacido.

Descriptores: Visita domiciliaria; Periodo posparto; Educación en salud.

\section{INTRODUÇÃO}

0 puerpério ou período pós-parto é definido como período após o nascimento, depois da expulsão da placenta, que se estende até 42 dias do parto. ${ }^{1}$ As visitas domiciliares (VD) neste período são ferramentas recomendadas pelo Ministério da Saúde (MS) para o melhor acompanhamento da saúde do Recém-Nascido (RN) e da puérpera, recomenda-se uma VD na primeira semana após a alta do bebê. Através das visitas, os profissionais de saúde são capazes de avaliar o estado de saúde da mulher e do RN, avaliar e desenvolver ações, e identificar e orientar de acordo com cada particularidade. $^{2}$

A puérpera se depara com os vários papeis sociais atribuídos às mulheres: cuidados com os filhos, com a família e com a casa. Além disso, elas lidam com dúvidas, medos e desconhecimentos sucedidos dessa fase, que influenciam sobremaneira em como vivem a experiência e a significam. ${ }^{3}$ Acrescenta-se a isso, o fato da mulher precisar manter sua vida profissional, concomitantemente aos papeis já mencionados. ${ }^{4}$ Deste modo, quanto mais informações essa mulher possuir, mais segura ela estará para significar o puerpério, ao mesmo tempo que desempenhar os demais papeis.

A VD por enfermeiros oferece à puérpera esclarecimento de dúvidas, orientações e identificação de possíveis anormalidades, acompanhando a mulher por todo o ciclo gravídico-puerperal. Além, de fortalecer o vínculo entre profissionais e puérpera/família, pois este acompanhamento no próprio domicílio favorece a aproximação, livre expressão de questionamentos relacionados à saúde ${ }^{5}$ e o cuidado por meio da educação em saúde, promovendo uma colaboração na assistência. ${ }^{6}$ 


\section{ISSN 2236 - 1987}

Dessa forma, a prática efetiva da VD puerperal realizada pelos enfermeiros é imprescindível na prevenção de doenças e agravos em saúde nesta fase, pois contribui para um cuidado integral, holístico e continuado. $^{7} 0$ presente estudo teve por objetivo identificar as principais vivências, necessidades e dúvidas de puérperas de um município do interior do Estado do Ceará (CE), com a finalidade de promover a saúde do binômio mãe-filho.

\section{MATERIAIS E MÉTODOS}

Estudo descritivo de caráter qualitativo no município de Acarape, que possui população estimada de 14.929 pessoas e 14 equipes de Estratégias de Saúde da Família. Foram realizadas VD para sete puérperas, durante os meses de abril e maio de 2015. Para isso, foi estabelecido vínculo com as mulheres de janeiro a março de 2015, durante a participação destas em um grupo de educação em saúde para gestantes no referido município.

Durante este período, as mulheres foram questionadas em relação à permissão e o interesse em receber visitas em suas residências no puerpério, solicitando o consentimento livre e esclarecido e preenchimento de fichas de inscrição contendo endereço residencial, data prevista do parto e registro de telefones para contato.

Antes de cada visita, as puérperas foram contatadas através de telefonemas, para confirmação do endereço e escolha do dia e horário, de acordo com a disponibilidade. Cada visita foi realizada por duas bolsistas, acadêmicas em enfermagem, com

duração de cerca de uma hora a uma hora e meia. 0 recurso utilizado na assistência domiciliar foi essencialmente um diálogo acessível com a puérpera e com seu/sua acompanhante, divididos em quatro categorias: impressões do parto e dúvidas com os acontecimentos no seu corpo no puerpério; atenção aos recém-nascidos; interação mãe e recém-nascido; planejamento familiar.

Diante disso, foram construídas técnicas educativas como forma de facilitar aprendizagem das puérperas e avaliar de modo satisfatório a interação da mãe com o RN. As técnicas educativas consistiram na observação, investigação e escuta a respeito do conhecimento das mulheres em relação ao autocuidado, cuidados com o RN e amamentação, assim orientações e demonstrações foram realizadas e experiências compartilhadas.

As VD foram observadas e registradas em diário de campo pelas duas pesquisadoras enquanto observadoras participantes. Durante as visitas, as falas das puérperas foram registradas e a identidade das participantes durante 0 estudo foi preservada, tendo os seus nomes substituídos por nome de pedras preciosas. A análise de conteúdo foi adotada como técnica para tratamento dos dados. ${ }^{8}$

Este estudo seguiu as normas para realização de pesquisas com seres humanos, ou seja, a Resolução 466/12, do Conselho Nacional de Saúde. ${ }^{9}$ Com aprovação do Comitê de Ética em Pesquisa sob o número do certificado 


\section{IOURNAIOF

de apresentação para Apreciação Ética 33807014.0.0000.5576.

\section{RESULTADOS}

As participantes do estudo estavam entre cinco e 42 dias pósparto durante a visita. Além de seus próprios domicílios, algumas mulheres encontravam-se na casa de familiares. A relação estabelecida entre pesquisadoras e gestantes durante a participação nos encontros do grupo educativo permitiu um maior interesse das mulheres de receber as VD.

Com a chegada das pesquisadoras à residência das puérperas, estas se mostraram receptivas e contentes em apresentar seus filhos, expressando nomes e o estado de saúde que se encontravam no momento. Foi orientado às puérperas que sentissem à vontade, a fim de evitar que alguma preocupação por parte delas interferisse no andamento da visita.

Impressões do parto e dúvidas com os acontecimentos no seu corpo no puerpério

As mulheres conversaram sobre a percepção dos sinais de parto; partilharam lembranças do seu parto, e a escolha do tipo de parto junto ao seu obstetra, evidenciados pelos seguintes relatos:

O pessoal fala tanto da dor do parto normal, mas ainda bem que pôde ser assim de novo, porque já estou podendo cuidar do bebê sozinha [...] a ajuda que tenho é porque tenho outra criança de três anos para cuidar. (Pérola)
É uma dor muito grande, o bom é que é rápido e não precisei ficar no hospital vários dias [relato referente ao parto normal]. (Safira)

As mulheres que tiveram parto normal expressaram momentos difíceis do trabalho de parto e parto, pois não puderam estar acompanhadas de seus parceiros em todo o período, foi relatado cansaço, fome, sede, enfatizando que essas sensações as deixaram abaladas e com vontade de desistir do parto normal.

Tratando-se da percepção de mudanças corporais, a maioria das mulheres que passaram por parto cesárea relatou uma boa recuperação quanto ao estado da incisão cirúrgica, entretanto, descreveram a grande limitação a que tiveram de ser submetidas devido à realização da cirurgia, fator que, segundo elas, dificulta bastante a realização do autocuidado e dos cuidados com o RN. Este relato foi evidenciado, principalmente, nos casos em que as puérperas não dispuseram de um auxílio adequado de familiares/amigos nos primeiros dias de puerpério. Como demonstrado na fala a seguir:

Às vezes a minha sogra vem me ajudar, mas não é todo dia. $O$ ruim da cesárea é isso [...] porque fico sozinha em casa, e fica difícil cuidar de tudo. (Turquesa)

Algumas informações voltadas aos sinais de parto repassados durante a gestação permitiram que as mulheres reconhecessem esse momento, inclusive as primíparas. Por isso, um fato comum, existente entre essas 


\section{NURSING \\ ANO HEALTH}

\section{r)}

mulheres consistiu na lembrança de algum momento que despertou a percepção dos sinais do parto.

Percepção esta, evidenciada nos depoimentos:

Quando vi aquele líquido descendo nas minhas pernas, parei um pouco, pensei e já imaginei o que era [...] chamei minha mãe para ir ao hospital. (Safira)

Dois dias antes do parto, me levantei e arrumei toda a casa, coisa que eu já não conseguia fazer há meses, ajeitei todas as roupas dele $e$ não me senti cansada [...] lembrei que tinham me dito no grupo dessa disposição de repente, já era um aviso que ele estava chegando. (Jaspe)

Além disso, em todas as visitas, as mulheres tinham queixas variadas, como: dor na pega da mama; mudança do horário de sono/repouso; não saber se está dando o banho de forma correta; não conseguir identificar quando o bebê está com fome, foram ouvidas e consideradas, assim, podendo descartar qualquer possibilidade de um processo patológico. De acordo com as queixas expostas, orientações foram direcionadas, objetivando a adequação da mulher a este período.

\section{Atenção aos recém-nascidos}

$\mathrm{Na}$ temática da atenção aos RN, os bebês foram inspecionados e as mães questionadas quanto à vacinação; pega da mama; alimentação; higienização; sono e repouso; eliminações vesicais; coto
ISSN 2236 - 1987

umbilical; cólicas abdominais. Os RN estavam com o cartão de vacinas atualizado. Quanto à pega da mama e aleitamento materno, a maioria estava amamentando exclusivamente, e mostraram-se satisfeitas com isso. Algumas primíparas expuseram que apresentavam um leve receio, tratando-se do banho ao RN e limpeza do coto umbilical. Como mostra a fala, a seguir:

Os primeiros banhos não tive coragem de dar, minha mãe que dava, mas agora estou aprendendo. (Jaspe)

Diante disso, orientações quanto aos procedimentos, além da explicação de que a limpeza do coto umbilical não dói e não machuca o bebê foram repassadas, como também a demonstração para a melhor posição do banho, evitando que entre água no ouvido e incomode o bebê. As mães mostraram-se receptivas às informações.

Determinadas puérperas relataram a ocorrência de cólicas abdominais nos $\mathrm{RN}$, e os métodos utilizados para tratamento:

Encosto a barriga dele na minha, me falaram que era bom quando o bebê estivesse com cólica. (Pérola)

Minha mãe fez um chá para diminuir as cólicas que ela estava sentindo, mas tive que usar remédios também, porque ela chorava muito. (Ametista)

Dessa forma, as puérperas mostraram certa dificuldade para compreender que o uso do chá retira o 
RN do aleitamento materno exclusivo, por isso, foi necessário um diálogo

na compreendiam os parâmetros fisiológicos, não necessitando de nenhum tipo de intervenção, além das orientações sobre cuidados básicos

(Figura 1).
Os achados e questionamentos, por parte das mães, em relação aos RN

Figura 1: Fluxograma sobre as principais dúvidas e as orientações realizadas. Acarape, 2018.
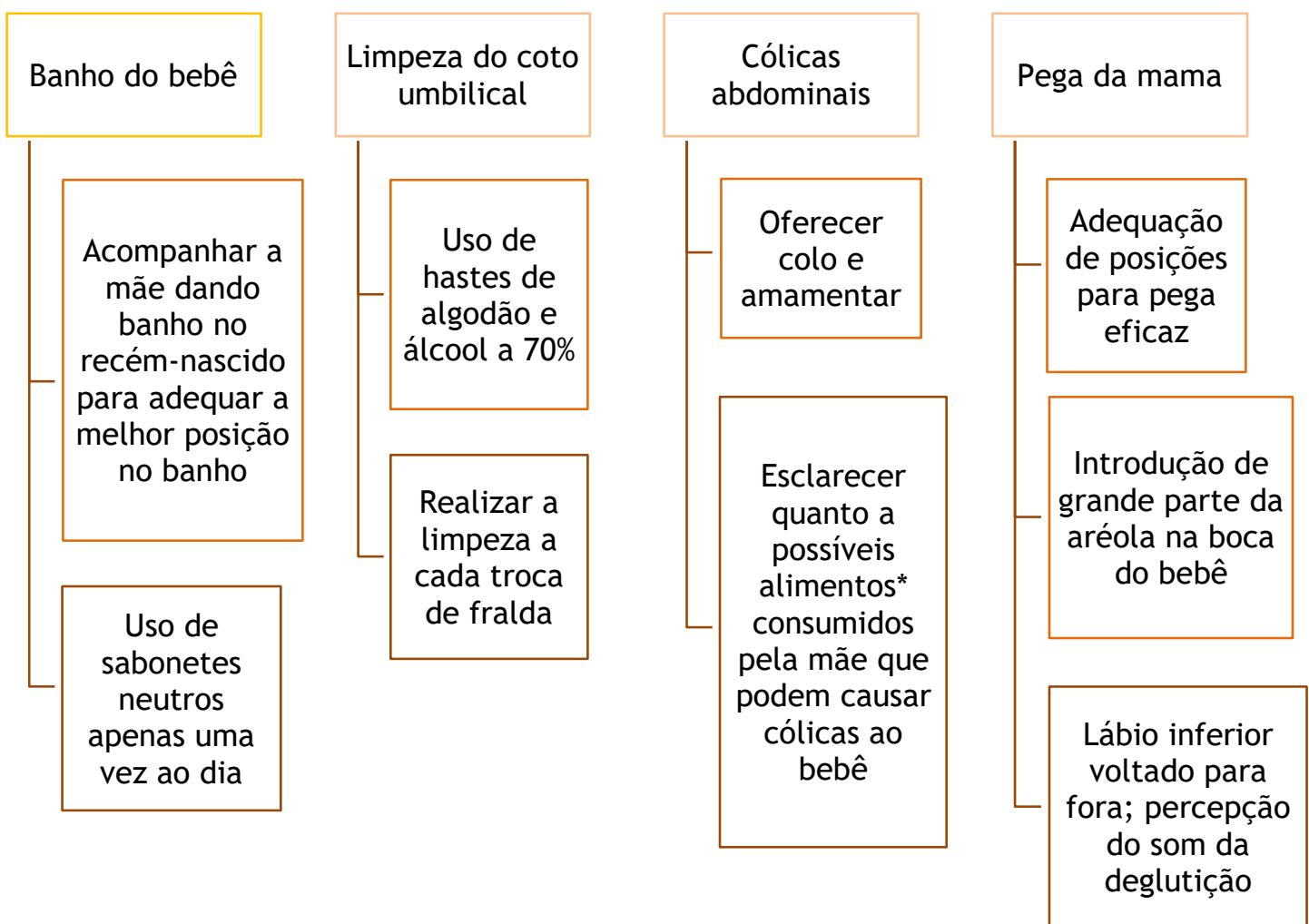

*De acordo com o MS, as mulheres que amamentam não necessitam evitar determinados alimentos, entretanto, se elas perceberem algum efeito na criança de algum componente de sua dieta, pode-se indicar a prova terapêutica, que consiste em retirar o alimento da dieta por algum tempo e reintroduzi-lo, observando atentamente a reação da criança. Caso os sinais e/ou sintomas da criança melhorem substancialmente com a retirada do alimento e piorem com a sua reintrodução, ele deve ser evitado. ${ }^{10}$

Fonte: elaborado pelos autores, 2018.

\section{Interação mãe e recém-nascido}

No tema abordado foi priorizada a importância do aleitamento materno para demonstrar os benefícios da amamentação exclusiva até o sexto mês, como também as vantagens da continuidade do aleitamento após o sexto mês do bebê que é quando se deve iniciar a introdução alimentar.

$\mathrm{Na}$ amamentação foi observada: a posição materna; posição do RN; busca e apreensão do conjunto mamilo areolar; frequência e o ritmo das sucções; irritabilidade do bebê; comportamento materno. As 
observações evidenciaram, em sua maioria, uma satisfatória interação entre mãe e RN, comprovada por um bom posicionamento do bebê e um comportamento materno tranquilo e atento (Figura 2).

Durante a lactação as mulheres dialogavam e iam explicando o significado e a boa satisfação daquele momento para si, como podemos compreender nos testemunhos:
Eu fico feliz em amamentar, às vezes dói e antes de pensar em parar eu já penso nos benefícios que vão ser para ele, quando estiver maiorzinho. (Ágata)

Tem dias que eu fico horas sentada amamentando, é um momento feliz a ver procurando pelo peito e depois bastante calma no meu colo. (Jade)

Figura 2: Interação da mãe-filho no momento da amamentação.

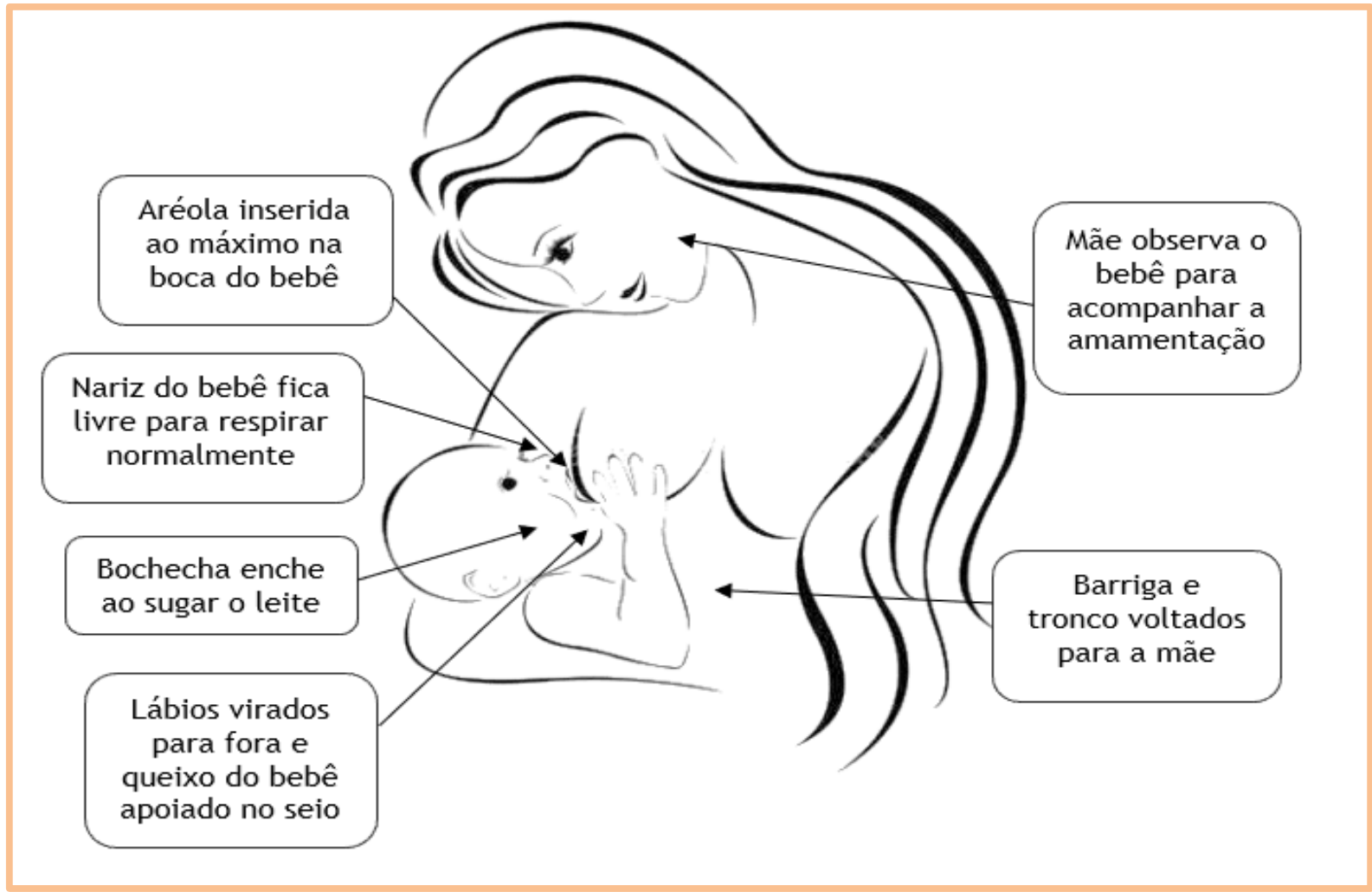

Fonte: Adaptado de Santiago, Santiago (2014). ${ }^{11}$

\section{Planejamento familiar}

O planejamento familiar foi um tema bastante questionado durante as visitas e através das explanações das mulheres foi apontado que algumas não almejavam ter mais filhos e as que desejavam ter queriam adiar uma próxima gestação. Os relatos a seguir demonstram as intenções reprodutivas das mulheres:

Já tenho dois, por mim já encerrava aqui, mas meu marido 


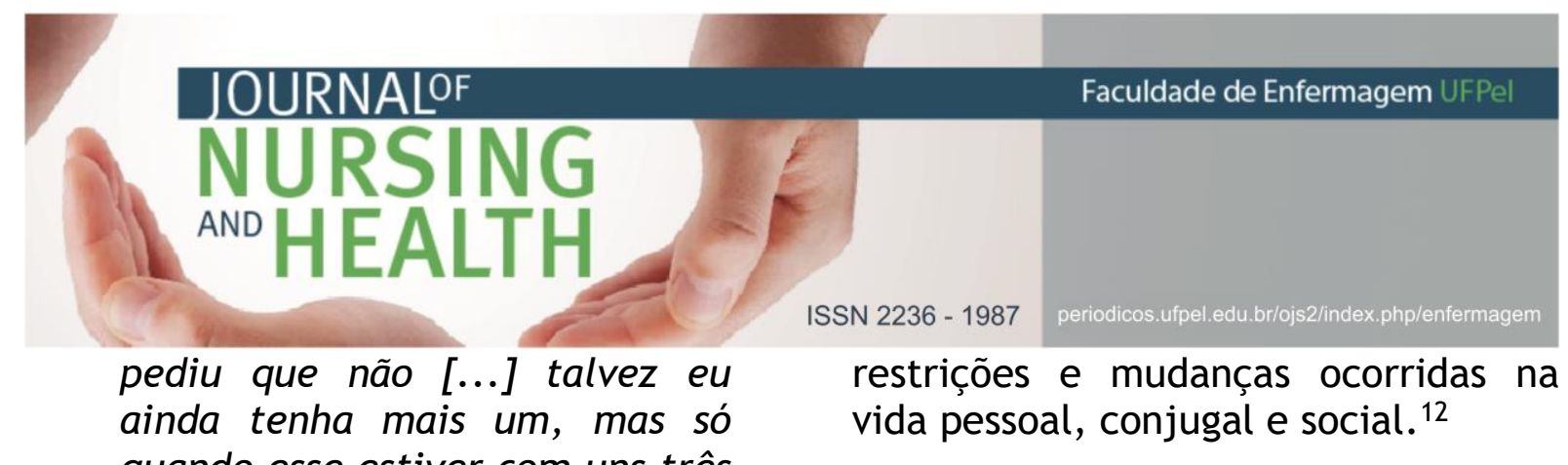
quando esse estiver com uns três anos. (Ametista)

Chega! Essa é a sexta, foi para encerrar a fábrica. (Jade)

Eu pensava em ter dois filhos, mas agora que ele nasceu eu estou vendo a quantidade de trabalho e de gastos, acho que vou parar por aqui ou demorar muito para eu ter outro. (Ágata)

Algumas puérperas relataram a preocupação com a anticoncepção e expuseram que iniciariam, assim que possível, à ingestão de anticoncepcionais. As mulheres demonstraram preferência pelo anticoncepcional injetável, relataram que nunca haviam utilizado 0 dispositivo intrauterino e não tinham interesse neste método. Apenas uma puérpera referiu que optaria por preservativo até iniciar outro método preventivo à gravidez.

Contudo, considerando que estas mulheres foram visitadas em seus primeiros dias de puerpério e estavam vivenciando de forma intensa a maternidade, o planejamento familiar deve ser abordado em outros momentos para compreensão de forma holística sobre os desejos do casal.

\section{DISCUSSÃO}

Percebe-se, que o puerpério é um fenômeno cercado de crenças, mitos e tabus repassados de geração a geração relacionados aos hábitos alimentares e atividades domésticas. As mulheres apresentam-se vulneráveis à vivência de sentimentos adversos, diante das

Além das modificações físicas, existem as emocionais, visto que após o parto os níveis do hormônio estrogênio no organismo materno caem bruscamente, podendo gerar uma tristeza ou uma complicação mais grave, como a depressão pós-parto, que é um problema latente e um campo aberto e amplo a ser explorado, sendo uma realidade cada vez mais constante no cotidiano de trabalho dos profissionais da atenção primária. Isso torna de suma importância o apoio e ações profissionais como uma rede de acolhimento. ${ }^{13} \mathrm{~A}$ equipe de saúde deve ser capaz de reconhecer os fatores de riscos, os sinais e os sintomas da depressão, planejar e executar ações preventivas, estabelecendo um relacionamento seguro e de empatia com a puérpera e sua família. ${ }^{14}$

Este fato ressalta a importância das visitas domiciliares, em que os profissionais envolvidos têm a possibilidade de trabalhar no processo de promoção da saúde, podendo desmitificar várias indagações, e, ainda encorajar o apoio familiar a essa mulher. ${ }^{15}$

A $1^{\text {a }}$ categoria do estudo corroborou os novos desafios que a mulher enfrenta, buscando informações sobre o estado de saúde da mãe e do RN, a fim de auxiliar no empoderamento de conhecimentos necessários no período pós-parto. ${ }^{16}$ Possibilitar a mulher o autocuidado e cuidado com seu filho de maneira segura e baseada em literatura científica se traduz em possibilitar um puerpério com mais chances de ser saudável para ambos. 


\section{JOURNALOF \\ NURSING \\ ANO HEALTH}

Sobre a escolha do tipo de parto, um estudo qualitativo realizado em Mato Grosso do Sul demonstrou fatores similares aos achados do presente estudo. Dentre eles: os diversos mecanismos institucionais, preferências particulares, escolhas coletivas, experiências anteriores, domínio médico e familiar, diálogo dos sujeitos que fazem parte de seu convívio social, receio da dor ou de complicações, qualidade do pré-natal na preparação física e psicológica da mulher, bagagem cultural, entre outras. ${ }^{17}$ Com isso, percebe-se que a escolha do tipo de parto, seja vaginal ou cirúrgico, ainda é permeada por muitos fatores, incluindo instituição e profissionais da saúde envolvidos, muitas vezes sendo determinada por estes, e não apenas as condições clínicas da parturiente.

Entretanto, o método de assistência domiciliar também enfrenta dificuldades. Estudo realizado nas Filipinas, demonstrou que a utilização inadequada do serviço de cuidados pós-parto pode estar relacionada às barreiras financeiras e ambientais, o que sugere que uma menor utilização de serviços de saúde essenciais pelas puérperas pode resultar em maiores sintomas anormais pós-parto. Desta forma, o estudo reforça a oferta de educação em saúde sobre sintomas de alerta, fator que pode melhorar o conhecimento e as atitudes das puérperas. ${ }^{18}$

Em relação a $2^{a}$ categoria, foi considerada a atenção aos RN, em que foram realizadas explanações acerca de eventos fisiológicos dos bebês que podem ser confundidos por processo patológico, concordando com outro
ISSN $2236-1987$

estudo, que destaca que a prática do enfermeiro no puerpério relacionado ao RN, deve consistir na observação e avaliação dos parâmetros fisiológicos para orientar a mãe sobre os cuidados com o bebê nos primórdios de sua vida. ${ }^{19}$

Os relatos descritos, no presente estudo, evidenciam a necessidade de informação e segurança que as puérperas apresentam nos primeiros dias, em relação, ao banho e à limpeza do coto umbilical. Cada mulher vivencia o puerpério de uma forma, o cuidado é dinâmico, e é preciso que o enfermeiro tenha subsídios teóricos e práticos para proporcionar cuidados possíveis/emergentes e não impostos, considerando um contexto em que crenças e costumes são, por vezes, colocados em primeiro lugar. Resultados que confirmam a importância da visita puerperal, para desenvolver estratégias de orientação que estimulem às mães a realização estes cuidados com segurança. ${ }^{20}$

Estudo realizado no município do Rio de Janeiro, com o objetivo de analisar os conhecimentos que os familiares adquirem sobre os cuidados com o RN antes e após participação em um grupo de acolhimento mãe-famíliabebê, demonstraram que cuidados também identificados no presente estudo, como o banho, limpeza do coto umbilical e cólicas, podem ser corretamente modificados através de ações de educação em saúde. ${ }^{21}$

Quanto a $3^{\mathrm{a}}$ categoria da pesquisa que trata da interação mãe-filho, a amamentação foi elencada como o principal meio desse elo. É importante ressaltar, que as orientações para a amamentação devem ser iniciadas 
durante o acompanhamento pré-natal, os profissionais de saúde devem estar plenamente engajados no incentivo ao aleitamento materno. ${ }^{22}$

Para o aleitamento se dar de modo satisfatório é necessário que além de orientações profissionais adequadas sobre o processo, a puérpera também receba adequado suporte familiar. ${ }^{23}$

A disposição para a amamentação e os conhecimentos básicos sobre a importância do leite materno apresentam-se como fatores que levam ao êxito do aleitamento materno. Dessa forma, as orientações serão eficazes para a prática continuada do aleitamento materno exclusivo. ${ }^{24}$

A $4^{a}$ categoria da pesquisa tratouse das questões relativas ao planejamento familiar que, por muitas vezes, é tratado de forma não integrada. Contudo, é importante a abordagem do planejamento familiar no pós-parto, desde a orientação até o fornecimento, pelo serviço de saúde. ${ }^{25}$ O MS recomenda que dentre as ações da VD, sejam realizadas atividades relacionadas à puérpera, sendo uma destas o diálogo sobre planejamento familiar. ${ }^{26}$

No entanto, um estudo realizado para compreender percepções e práticas relativas ao acolhimento no cuidado puerperal à mulher, os resultados destacaram uma insatisfação com a VD: assistemática e descontinuada. As puérperas relataram um desconforto pela atenção focalizada no bebê. ${ }^{27}$

Deste modo, verifica-se que a VD é uma ferramenta eficaz para o acompanhamento do binômio mãe- filho no puerpério, mas que a mesma precisa ser pautada em pontos específicos do cuidado e deve ser ampla visando o cuidado a família.

\section{CONSIDERAÇÕES FINAIS}

As visitas domiciliares proporcionaram a discussão de temas importantes para as puérperas, complementando as informações recebidas no atendimento pré-natal, de modo a torná-las mais empoderadas para enfrentar os desafios do autocuidado e do cuidado com o filho RN. Nesse contexto, o profissional enfermeiro propicia o esclarecimento de dúvidas, orientações e identificação de possíveis anormalidades, além de favorecer 0 vínculo profissional/puérpera/família.

Baseado nestas evidências, o presente estudo reforça a necessidade de uma avaliação da qualidade da assistência domiciliar realizada atualmente, a fim de analisar se os passos realizados condizem com 0 direcionamento exigido pelo puerpério, visto que, este período inclui, não somente a puérpera e o RN, mas todos os que participam ativamente de cuidados ou orientações.

Os resultados do estudo também remetem a importância de questões relacionadas à organização de visitas domiciliares, visto que, para sua realização de maneira eficaz é necessária uma rede de cuidados integrada e atuante de gestores, profissionais da saúde e comunidade, para que questões sociais sejam consideradas e recursos de acesso com segurança ao domicílio estejam disponíveis. 


\section{JOURNALOF \\ NURSING \\ AND $\square$ 드는}

Diante do exposto, enfatiza-se a necessidade de novos estudos, a fim de explorar a presente temática, envolvendo gestão, planejamento e operacionalização necessária a essa prática, que apresenta grande contribuição na promoção da saúde do binômio mãe-filho. As limitações do estudo foram relacionadas à comunicação e ao acesso aos domicílios, pois algumas mulheres encontravam-se na casa de familiares, ou residiam em locais de difícil acesso.

\section{REFERÊNCIAS}

1 Montenegro $\mathrm{CAB}$, Rezende Filho J. Obstetrícia Fundamental. $13^{\mathrm{a}}$ ed. Rio de Janeiro: Guanabara Koogan; 2014.

2 Ministério da Saúde (BR). Pré-natal e Puerpério: atenção qualificada e humanizada [Internet]. Brasília; 2006[acesso em 2019 out 22]. Disponível em: http://bvsms.saude.gov.br/bvs/public acoes/manual_pre_natal_puerperio_3 ed.pdf

3 Teixeira RC, Mandú ENT, Corrêa ACP, Marcon SS. Necessidades de saúde de mulheres em pós-parto. Esc. Anna Nery Rev. Enferm. [Internet]. 2015 out/dez[acesso em 2019 ago 21];19(4):621-8. Disponível em: http://www.scielo.br/pdf/ean/v19n4 /1414-8145-ean-19-04-0621.pdf

4 Tavares AD, Barbosa RB. A mulher e a tripla jornada de trabalho: como esta mulher vivencia as atividades profissional, familiar e doméstica? Psicologia em foco [Internet]. 2015 jan/jun[acesso em 2019 ago 21];5(1):2-10. Disponível em: http: / / docplayer.com.br/27167067-Amulher-e-a-tripla-jornada-detrabalho-como-esta-mulher-vivencia-
ISSN 2236 - 1987

as-atividades-profissional-familiar-edomestica.html

5 Silva LLB, Feliciano KVO, Oliveira LNFP, Pedrosa EN, Corrêa MSM, Souza Al. Cuidados prestados à mulher na visita domiciliar da "Primeira Semana de Saúde Integral". Rev. gaúcha enferm. [Internet]. 2016 set[acesso em 2018 ago 10];37(3):1-9. Disponível em: http: / /www.scielo.br/pdf/rgenf/v37n 3/0102-6933-rgenf-1983144720160359248.pdf

6 Cassiano AN, Holanda CSM, Costa RKS, Morais FRR, Maranhão TMO. Assistência de enfermagem à mulher no puerpério imediato: um ensaio descritivo. Rev. Pesqui. (Univ. Fed. Estado Rio J., Online). [Internet]. 2015 jan/mar[acesso em 2019 ago 21];7(1): 2061-71. Disponível em: http://www.seer.unirio.br/index.php /cuidadofundamental/article/downlo ad/3675/pdf_1455

7 Medeiros LS, Costa ACM. Período puerperal: a importância da visita domiciliar para enfermeiros da Atenção Primária à Saúde. Rev Rene (Online) [Internet]. 2016 jan/fev[acesso em 2019 ago 22];17(1):112-9. Disponível em: http://periodicos.ufc.br/rene/article /view/2622/2009

8 Bardin L. Análise de conteúdo. São Paulo: Edições 70; 2011.

9 Ministério da Saúde (BR). Conselho Nacional de Saúde. Resolução 466, de 12 de dezembro de 2012: diretrizes e normas regulamentadoras de pesquisa envolvendo seres humanos. Brasília; 2012.

10 Ministério da Saúde (BR). Cadernos de atenção básica n. 23. Saúde da criança: aleitamento materno e 


\section{NURSING \\ AND}

ISSN 2236 - 1987

enfermeiro da estratégia de saúde da família como promotor do aleitamento materno. Rev. Contexto Saude (Impr.) [Internet]. 2016[acesso em 2017 out 17];16(31):16-24. Disponível em: https: / /www.revistas.unijui.edu.br/in dex.php/contextoesaude/article/dow nload/5967/5135

16 Luz VLES, Sales JCS, Siqueira MLS, Vieira TS, Coêlho DMM, Barbosa MG. Assistência do enfermeiro da Estratégia Saúde da Família na visita domiciliar à puérpera. Revista interdisciplinar UNINOVAFAPI [Internet]. $2016 \mathrm{fev} / \mathrm{mar}$ [acesso em 2017 out 17];9(1):13-23. Disponível em:

https://revistainterdisciplinar.uninova fapi.edu.br/index.php/revinter/articl e/view/552/pdf_280

17 Nascimento RRP, Arantes SL, Souza EDC, Contrera L, Sales APA. Escolha do tipo de parto: fatores relatados por puérperas. Rev. gaúcha enferm. [Internet]. 2015[acesso em 2017 out 17];36(esp):119-26. Disponível em: http://www.scielo.br/pdf/rgenf/v36n spe/0102-6933-rgenf-36-spe-0119.pdf

18 Yamashita T, Tuliao MTR, Meana MC, Suplido SA, Llave CL, Tanaka Y, et al. Utilization of healthcare services in postpartum women in the Philippines who delivered at home and the effects on their health: a cross-sectional analytical study. Int J Womens Health [Internet]. 201 [cited 2019 Aug 19];9:695-700. Avalaible from: https://www.ncbi.nlm.nih.gov/pmc/a rticles/PMC5627794/pdf/ijwh-9695.pdf

19 Santos ACC, Ferreira EJ, Santos L, Souza OSQ. Relato de experiência no contexto da educação em saúde o Menezes Júnior CC, Rodrigues MENG. 0 


\section{NURSING \\ AND \\ HEALTH}

cuidado materno infantil. Rev. enferm. UFPE on line. [Internet]. 2015[acesso em 2017 out 17];9(5):8474-78. Disponível em: https://periodicos.ufpe. br/revistas/r evistaenfermagem/article/viewFile/1 0615/11599

20 Fornari MCB, Carraro TE, Roque ATF, Massaroli A. Cuidado de enfermagem à puérpera no domicílio na perspectiva do modelo de cuidado de Carraro. Rev. Enferm. UFSM. [Internet]. $2016 \mathrm{abr} /$ jun[acesso em 2019 ago 19];6(2):175-85. Disponível em:

https://periodicos.ufsm.br/reufsm/ar ticle/download/17752/pdf

21 Rolim KMC, Cavalcante RC, Cavalcante JF, Pinheiro CW, Magalhães FJ, Abreu FH, et al. Conhecimentos de familiares sobre os cuidados com recém-nascidos. Rev Rene (Online) [Internet]. $2015 \mathrm{mar} / \mathrm{abr}$ [acesso em 2017 dez 10];16(2):258-65. Disponível em:

http://www.periodicos.ufc.br/rene/a rticle/view/2722/2106

22 de Sá FMDL, Alves VH, Rodrigues DP, Guerra JVV, Pereira AV, Branco MBLR. Imagens do ato de amamentar como cuidado em saúde: a percepção das próprias nutrizes. J. nurs. health. [Internet]. 2019[acesso em 2019 out 22];9(1):e199110. Disponível em: https://periodicos.ufpel.edu.br/ojs2/ index.php/enfermagem/article/view/ 15945/10153

23 Ferraz L, Oliveira PP, Antoniolli MA, Benedett A, Bossetti V, Almeida $\mathrm{K}$. Opinião de mulheres sobre a participação do pai no aleitamento materno. Arq. ciências saúde UNIPAR. [Internet]. 2016 maio/ago[acesso em
ISSN 2236 - 1987

2017 dez 10];20(2):95-9. Disponível em:

https: / / revistas.unipar.br/index.php/ saude/article/download/4674/3300

24 Huang P, Ren J, Liu Y, Luo B, Zhao $X$. Factors affecting breastfeeding adherence among Chinese mothers: A multicenter study. Medicine (Baltimore) [Internet]. 2017 Sept[cited 2019 Aug 10];96(38):1-6. Avaliable from:

https://www.ncbi.nlm.nih.gov/pmc/a rticles/PMC5617685/

25 Andrade RD, Santos JS, Maia MAC, Mello DF. Factors related to women's health in puerperium and repercussions on child health. Esc. Anna Nery Rev. Enferm. [Internet]. 2015 Jan/Feb[cited 2019 Aug 20];19(1):181-6. Avaliable from: http://www.scielo.br/pdf/ean/v19n1 /en_1414-8145-ean-19-01-0181.pdf

26 Ministério da Saúde (BR). Cadernos de atenção básica $n^{\circ} 32$. Atenção ao pré-natal de baixo risco [Internet]. Brasília; 2012[acesso em 2019 out 22]. Disponível em: http://bvsms.saude.gov.br/bvs/public acoes/cadernos_atencao_basica_32_p renatal.pdf

27 Corrêa MSM, Feliciano KVO, Pedrosa EN, Souza Al. Acolhimento no cuidado à saúde da mulher no puerpério. Cad. Saúde Pública (Online). [Internet]. 2017[acesso em 2017 dez 09];33(3):112. Disponível em: http://www.scielo.br/pdf/csp/v33n3 /1678-4464-csp-33-03-e00136215.pdf

Data de submissão: 29/08/2019

Data de aceite: 30/10/2019

Data de publicação: 18/11/2019 